\title{
Second-generation proteasome inhibitor carfilzomib enhances doxorubicin-induced cytotoxicity and apoptosis in breast cancer cells
}

\author{
Yonghua Shi ${ }^{1,2,3}$, Yang Yư ${ }^{3,4}$, Zhenyu Wang ${ }^{2,3,5}$, Hao Wang ${ }^{2,3,6}$, Shayahati \\ Bieerkehazhi ${ }^{2,3,7}$, Yanling Zhao ${ }^{8}$, Lale Suzuk ${ }^{1}$, Hong Zhang ${ }^{2,3}$ \\ ${ }^{1}$ Department of Pathology, Basic Medicine College, Xinjiang Medical University, Urumqi, Xinjiang 830011, China \\ ${ }^{2}$ Department of Pathology, The University of Texas MD Anderson Cancer Center, Houston, Texas 77030, USA \\ ${ }^{3}$ Department of Translational and Molecular Pathology, The University of Texas MD Anderson Cancer Center, Houston, Texas \\ 77030, USA \\ ${ }^{4}$ Laboratory of Medical Genetics, Harbin Medical University, Harbin, Heilongjiang 150081, China \\ ${ }^{5}$ Department of Breast Surgery, The Second Hospital of Jilin University, Changchun, Jilin 130041, China \\ ${ }^{6}$ Department of Hepatopancreatobiliary Surgery, the Second Affiliated Hospital of Harbin Medical University, Harbin, \\ Heilongjiang 150086, China \\ ${ }^{7}$ College of Public Health, Xinjiang Medical University, Urumqi, Xinjiang 830011, China \\ ${ }^{8}$ Texas Children's Cancer Center, Department of Pediatrics, Dan L. Duncan Cancer Center, Baylor College of Medicine, \\ Houston, Texas 77030, USA \\ Correspondence to: Hong Zhang, email: HZhang9@mdanderson.org \\ Keywords: proteasome inhibitor, carfilzomib, doxorubicin, drug resistance, breast cancer \\ Abbreviations: PI, proteasome inhibitor; CFZ, carfilzomib; DOX, doxorubicin; DMSO, dimethyl sulfoxide; FDA, Food and Drug \\ Administration \\ Received: June 07, $2016 \quad$ Accepted: August 26, $2016 \quad$ Published: September 15, 2016
}

\section{ABSTRACT}

Proteasome inhibition is an attractive approach for anticancer therapy. Doxorubicin (DOX) is widely used for treatment in a number of cancers including breast cancer; however, the development of DOX resistance largely limits its clinical application. One of the possible mechanisms of DOX-resistance is that DOX might induce the activation of NF-KB. In this case, proteasome inhibitors could inhibit the activation of NF-kB by blocking inhibitory factor KB (IKB) degradation. Carfilzomib, a second-generation proteasome inhibitor, overcomes bortezomib resistance and lessens its side-effects. Currently, the effect of carfilzomib on breast cancer cell proliferation remains unclear. In this study, we exploited the role of carfilzomib in seven breast cancer cell lines, MCF7, T-47D, MDA-MB-361, HCC1954, MDA-MB-468, MDA-MB-231, and BT-549, representing all major molecular subtypes of breast cancer. We found that carfilzomib alone had cytotoxic effects on the breast cancer cells and it increased DOX-induced cytotoxic effects and apoptosis in combination by enhancing DOX-induced JNK phosphorylation and inhibiting DOX-induced IKBa degradation. The results suggest that carfilzomib has potent antitumor effects on breast cancer in vitro and can sensitize breast cancer cells to DOX treatment. DOX in combination with carfilzomib may be an effective and feasible therapeutic option in the clinical trials for treating breast cancer.

\section{INTRODUCTION}

The proteasome is a protease complex that plays a central role in cellular activities, including the processing of misfolded, unassembled, or damaged intracellular proteins [1]. Its inhibition leads to the accumulation of substrate proteins and, ultimately, cell death [2]. Over the last several decades, proteasome inhibition has been extensively investigated as a selective anti-cancer strategy and validated in clinical trials using first- and 
second-generation proteasome inhibitors (PIs)[3]. The mechanisms of the antitumor activity of PIs are inhibition of proteasome activity, down-regulation of nuclear factor $\kappa \mathrm{B}(\mathrm{NF}-\kappa \mathrm{B})$ signaling through blocking inhibitory factor $\kappa \mathrm{B}(\mathrm{I} \kappa \mathrm{B})$ degradation, induction of cancer cell apoptosis through production of the pro-apoptotic factor tumor necrosis factor alpha (TNF- $\alpha)$, stabilization of $\mathrm{p} 53$, and interference with a number of different cell cycle signaling pathways, e.g. AKT, MAPK, and c-Jun [4, 5].

Proteasome inhibition has proven to be an effective therapeutic strategy for multiple myeloma and mantle cell lymphoma [6, 7]. Bortezomib, a first-generation PI, was the first to be approved by the US Food and Drug Administration (FDA) for treatment of multiple myeloma in 2003 and relapsed or refractory mantle cell lymphoma in 2006 [8]. Second-generation PI carfilzomib (CFZ, PR$171)$ is the second FDA-approved PI for the treatment of recurrent multiple myeloma [9]. CFZ is an irreversible tetrapeptide epoxyketone PI that selectively inhibits the chymotrypsin-like activity of the constitutive $20 \mathrm{~S}$ proteasome and the immunoproteasome [2]. Compared to bortezomib, CFZ has minimal off-target effects on nonproteasome, serine proteases which is thought to explain its reduced neurotoxicity as compared to that of other PIs [10]. CFZ overcomes bortezomib resistance and lessens side effects in patients treated with bortezomib [9]. These agents have also been studied in solid tumors in a number of phase I and II clinical trials [11, 12], yet they have not shown consistent antitumor activity in solid tumors. At present, the effect of carfilzomib on breast cancer cell proliferation remains unclear.

Breast cancer is a common malignancy affecting women of all ages [13]. While targeted therapy has proven effective in a subset of breast cancer patients, new molecularly targeted agents are necessary for breast cancer patients whose tumors develop resistance to chemotherapy. Doxorubicin (DOX, Adriamycin), an anthracycline, inhibits DNA/RNA synthesis by intercalation between base pairs of DNA strands, inducing apoptosis of tumor cells. Despite the wide use of DOX in cancer treatment, acquired drug resistance and profound cytotoxicity largely limits its clinical application potential [14, 15]. Hence, combined treatment with some sensitizing agent is desirable to overcome the resistance to DOX and increase the antitumor effects. One of the explanations for DOX resistance is that DOX could induce the activation of NF$\kappa \mathrm{B}$ [16]. PIs are known to selectively target cancer cells and make them more sensitive to chemotherapeutic agents. Given the potential for improved efficacy and greater tolerability of CFZ and CFZ's known down-regulation of nuclear factor $\kappa \mathrm{B}(\mathrm{NF}-\kappa \mathrm{B})$ signaling, we investigated the antitumor activity of CFZ in a panel of molecularly unique breast cancer cell lines alone or in combination with DOX. Here we report that CFZ alone resulted in potent inhibition of cellular proliferation and induction of apoptosis, sensitized cells to DOX-induced toxicity, and intensified DOX-induced apoptosis in combination across a diverse set of breast cancer cell lines in vitro.

\section{RESULTS}

\section{Carfilzomib suppresses the proliferation of breast cancer cells}

To assess the anti-tumor effect of CFZ on breast cancer cells, seven breast cancer cell lines, including MCF7, T-47D, MDA-MB-361, HCC1954, MDAMB-468, MDA-MB-231, and BT-549 were used, which together represent the major molecular subtypes of breast cancer (Table 1) [17-19]. These cells were treated with CFZ at the indicated concentrations of $0.001 \mu \mathrm{M}$ to $50 \mu \mathrm{M}$ for $72 \mathrm{~h}$, then subjected to an MTT assay. The results showed that carfilzomib reduced the cell viability of all types of tested breast cancer cells in a dose-dependent manner (Figure 1). The IC50s of CFZ were between $6.34 \mathrm{nM}$ (MDA-MB-361) and $76.51 \mathrm{nM}$ (T-47D) (Figure 1). The cytotoxic effect of CFZ was confirmed by morphological changes of the cells after treatment for $72 \mathrm{~h}$ (Supplementary Figure S1a). Since the IC50s were around the doses of $0.01 \mu \mathrm{M}$ and 0.05 $\mu \mathrm{M}$ within all cell lines, we only showed the data for these two doses.

To further validate the inhibitory effect of CFZ on cell proliferation, a cellular colony formation assay was performed. The cells were treated with CFZ at the concentrations of $0 \mu \mathrm{M}, 0.005 \mu \mathrm{M}$ and $0.01 \mu \mathrm{M}$ for $72 \mathrm{~h}$ and then cultured in drug-free medium for about two weeks. Carfilzomib treatment remarkably inhibited the cellular proliferation compared to the control groups (Supplementary Figure S1b). These data indicate that CFZ has a potent inhibitory effect on the proliferation of breast cancer cells, regardless of molecular subtypes.

\section{Carfilzomib restrains the anchorage- independent growth of breast cancer cells}

Cancer cells possess the ability to grow into ballshaped colonies in a three dimensional space when cultured in soft agar. To evaluate whether carfilzomib could impair the anchorage-independent growth ability of breast cancer cells, soft agar assays were performed. Here, breast cancer cells, including MCF7, T-47D, MDAMB-361, MDA-MB-468, MDA-MB-231, and BT-549, were cultured with $\mathrm{CFZ}$ at $0 \mu \mathrm{M}, 0.005 \mu \mathrm{M}$ and 0.01 $\mu \mathrm{M}$ for three weeks. After that, the visible colonies were fixed and stained. The anchorage-independent growth ability of HCC1954 cell line was too weak to form visible colonies in soft agar, so the data for this cell line is not shown. The number of colonies decreased in CFZ-treated groups compared to the control cells in the tested cell lines (Figure 2a). The inhibitory effects of CFZ on colony 
Table 1: Molecular classification of the human breast cancer cell lines [17-19]

\begin{tabular}{lcccccc}
\hline Cell line & Subtype & ER & PR & HER2 & Source & Tumor type \\
\hline MCF7 & LuA & + & {$[+]$} & - & PE & IDC \\
T-47D & LuA & + & {$[+]$} & - & PE & IDC \\
MDA-MB-361 & LuB & + & {$[-]$} & + & P.Br & AC \\
HCC1954 & HER2 & - & {$[-]$} & + & P.Br & Duc.Ca \\
MDA-MB-468 & $\mathrm{BaA}$ & {$[-]$} & {$[-]$} & - & PE & AC \\
MDA-MB-231 & $\mathrm{BaB}$ & - & {$[-]$} & - & $\mathrm{PE}$ & $\mathrm{AC}$ \\
BT-549 & $\mathrm{BaB}$ & - & {$[-]$} & - & $\mathrm{P.Br}$ & IDC, pap \\
\hline
\end{tabular}

AC, adenocarcinoma; BaA, Basal A; BaB, Basal B; Ca, carcinoma; Duc.Ca, ductal carcinoma; IDC, invasive ductal carcinoma; Lu, luminal; Pap, papillary; P.Br, primary breast cancer; PE, pleural effusion.

ER/PR/HER2 status: ER/PR positivity, and HER2 overexpression (obtained from the Sanger web site) are indicated. Square brackets indicate that levels are inferred from mRNA levels alone where protein data are not available.

formation were dose-dependent and statistically significant in CFZ- treated cells (Figure 2b).

\section{Carfilzomib induces apoptosis in breast cancer cells}

It has been reported that CFZ can induce apoptosis in a variety of tumor types, including lung cancer, melanoma, and chronic lymphocytic leukemia $[11,20$, 21]. To examine whether CFZ could induce apoptosis in human breast cancer cells, the cells were treated with CFZ at concentrations of $0,0.01 \mu \mathrm{M}, 0.05 \mu \mathrm{M}, 0.1 \mu \mathrm{M}$ and $1 \mu \mathrm{M}$, respectively, and then harvested and subjected to immunoblotting. Since MCF7 cells are Caspase 3 deficient, we tested Caspase 7 as the alternative. We found that CFZ could induce the cleavage of PARP and Caspase 3 (or Caspase 7) in the tested cell lines in a dose-dependent manner except MDA-MB-361, MDA-MB-468 and MDAMB-231 cell lines (Figure 3a-3g). To further verify that carfilzomib could induce apoptosis in MDA-MB-361, MDA-MB-468 and MDA-MB-231 cell lines, the cells were treated with $\mathrm{CFZ}$ at concentrations of $0,0.05 \mu \mathrm{M}$, and $1 \mu \mathrm{M}$, respectively, and then harvested and subjected to flow cytometry (Supplementary Figure S2a-S2c). The results showed that CFZ could induce apoptosis in the tested cell lines in a dose-dependent manner. Altogether, the results suggest that carfilzomib alone could trigger apoptosis in breast cancer cells.

\section{Carfilzomib intensifies the cytotoxic effect of DOX on breast cancer cells}

To verify whether CFZ and DOX have synergistic effects on breast cancer cells, the cells were cultured in the increased concentration of $0,0.05 \mu \mathrm{M}, 0.1 \mu \mathrm{M}, 0.2 \mu \mathrm{M}$, $0.5 \mu \mathrm{M}$ or $1 \mu \mathrm{M}$ of DOX alone or in combination with 0.01 $\mu \mathrm{M}$ of carfilzomib for $72 \mathrm{~h}$, and the cell proliferation was assessed by MTT assay. Cytotoxic effects of $0.01 \mu \mathrm{M}$ of carfilzomib alone on MDA-MB-231 and BT-549 cell lines were very strong, so we used $0.005 \mu \mathrm{M}$ of carfilzomib as the alternative. The results showed that the cell viabilities were much lower when treated with the combination compared to those treated with DOX alone (Figure 4a$4 \mathrm{~g}$ ). The combination indexes (CIs) for most combinations were far lower than 1.0, indicating synergistic effects on breast cancer cells (Figure 4a-4g). It implies that CFZ could sensitize the cytotoxicity of DOX on the tested cell lines.

\section{Carfilzomib enhances the DOX-induced apoptosis in breast cancer cells}

To explore whether CFZ could strengthen DOXinduced apoptosis in breast cancer cells, the cells were treated with DOX alone $(1 \mu \mathrm{M})$ or combined with carfilzomib at $0.05 \mu \mathrm{M}$ (lower dose) for $0,16 \mathrm{~h}$, or 24 h. Immunoblotting analyses demonstrated that CFZ could boost DOX-induced PARP and Caspase 3 (or Caspase 7) cleavage in all subtypes of breast cancer cell lines tested (Figure 5a-5g). This indicates that CFZ could intensify DOX-induced apoptosis in breast cancer cells.

\section{Activation of JNK, but not p38 MAPK, and inactivation of NF- $\kappa B$ is required for carfilzomib boosting DOX-induced apoptosis in breast cancer cells}

Both NF-kB and MAPK are key signal transduction pathways in regulating cell survival [21-24]. Studies have revealed that DOX could induce NF- $\mathrm{kB}$ and MAPK activation $[16,25,26]$; meanwhile proteasome inhibitors could inhibit the activation of NF- $\mathrm{kB}$ [27]. To better 


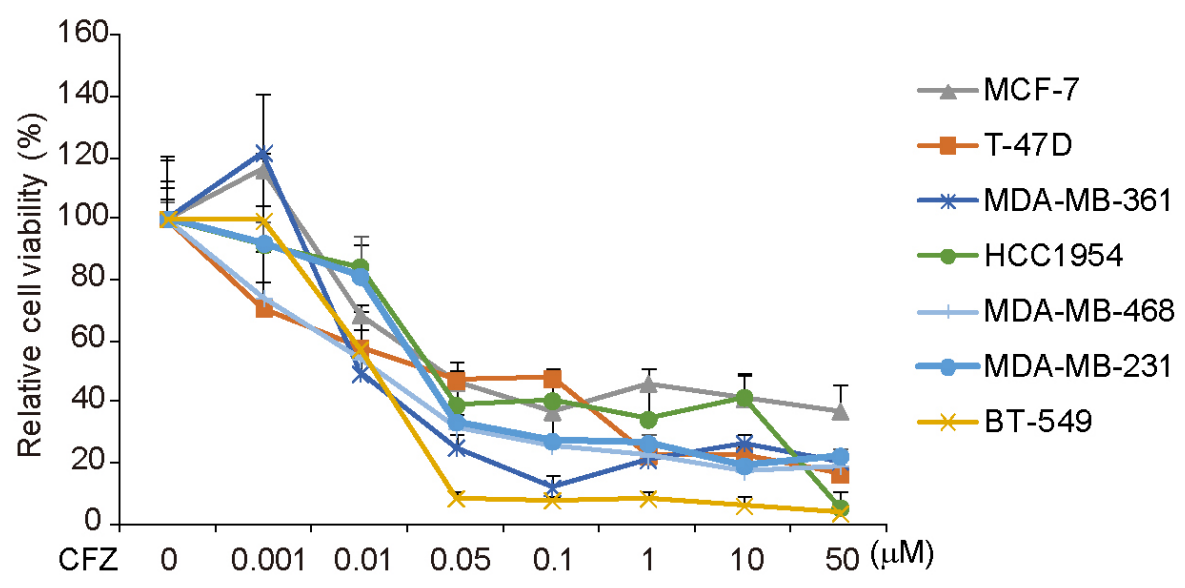

IC50 of CFZ in breast

cancer cell lines

Cell lines IC50 (nM)

MCF7 6.72

T-47D $\quad 76.51$

MDA-MB-361 6.34

HCC1954 21.35

MDA-MB-468 14.40

MDA-MB-231 22.36

BT-549 $\quad 10.80$

Figure 1: Carfilzomib shows cytotoxic effects on breast cancer cells. Cytotoxic effects of carfilzomib on breast cancer cells in MTT assays. Seven human breast cancer cell lines, MCF7, T-47D, MDA-MB-361, HCC1954, MDA-MB-468, MDA-MB-231, and BT-549 were treated with carfilzomib at $0,0.001 \mu \mathrm{M}, 0.01 \mu \mathrm{M}, 0.05 \mu \mathrm{M}, 0.1 \mu \mathrm{M}, 1 \mu \mathrm{M}, 10 \mu \mathrm{M}$, or $50 \mu \mathrm{M}$ for $72 \mathrm{~h}$, then subjected to MTT assays. The absorbance of each well was measured at $540 \mathrm{~nm}$ and plotted for the cell viability curve. IC50 values of carfilzomib in breast cancer cell lines were listed.

a

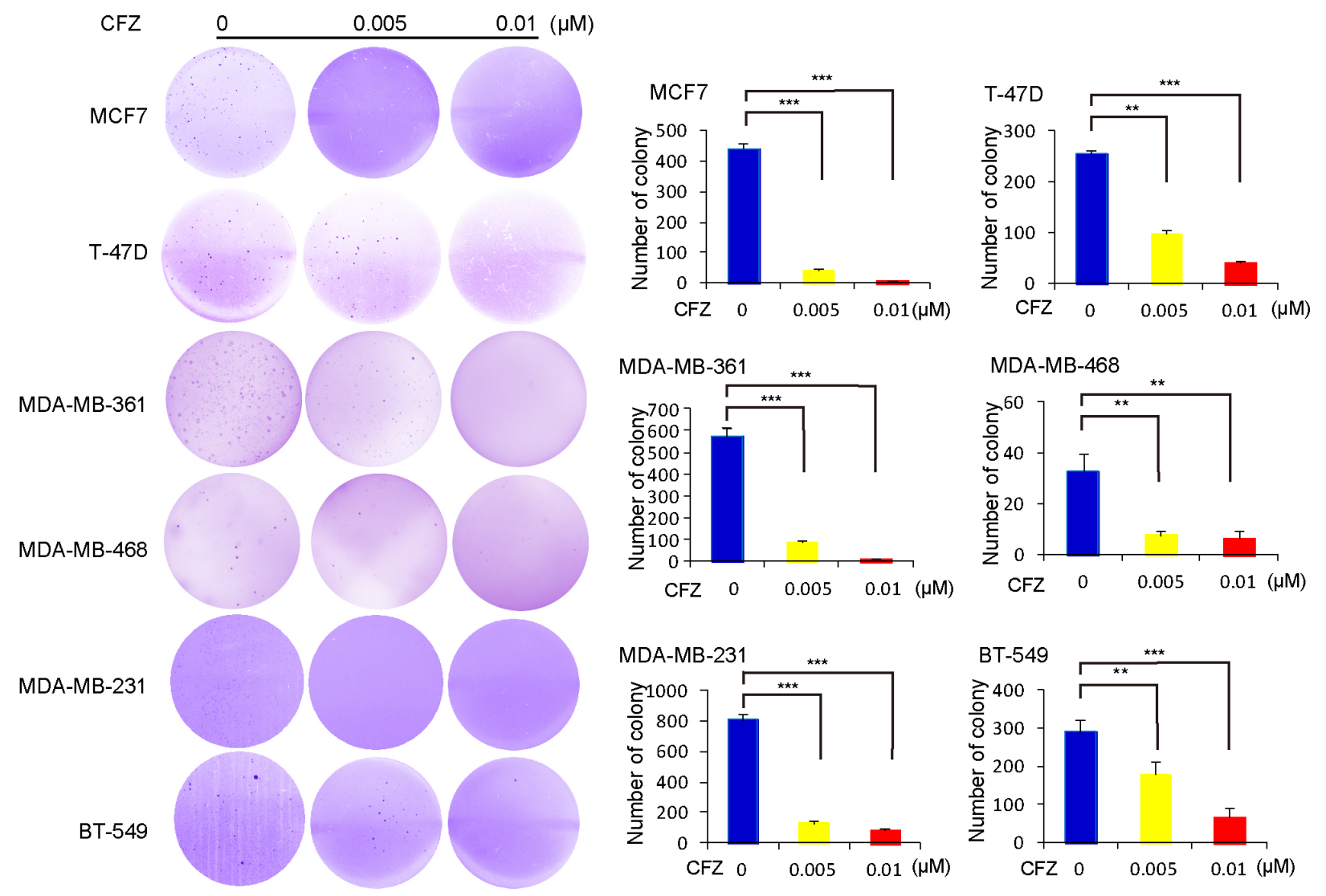

Figure 2: Carfilzomib suppresses the anchorage-independent growth ability of breast cancer cells. Cell anchorageindependent growth ability was assessed by soft agar assays. a. Six breast cancer cell lines, MCF7, T-47D, MDA-MB-361, MDA-MB-468, MDA-MB-231, and BT-549 were incubated with carfilzomib at $0,0.005 \mu \mathrm{M}$, or $0.01 \mu \mathrm{M}$ in soft agar plates for three weeks, stained with crystal violet and photographed. b. The colonies of (a) were counted and plotted. Data are represented as mean $\pm \mathrm{SD}$. * indicates $P<0.05$, ** indicates $P<0.01, * * *$ indicates $P<0.001$, by ANOVA and Dunnett's multiple comparison post-test. 

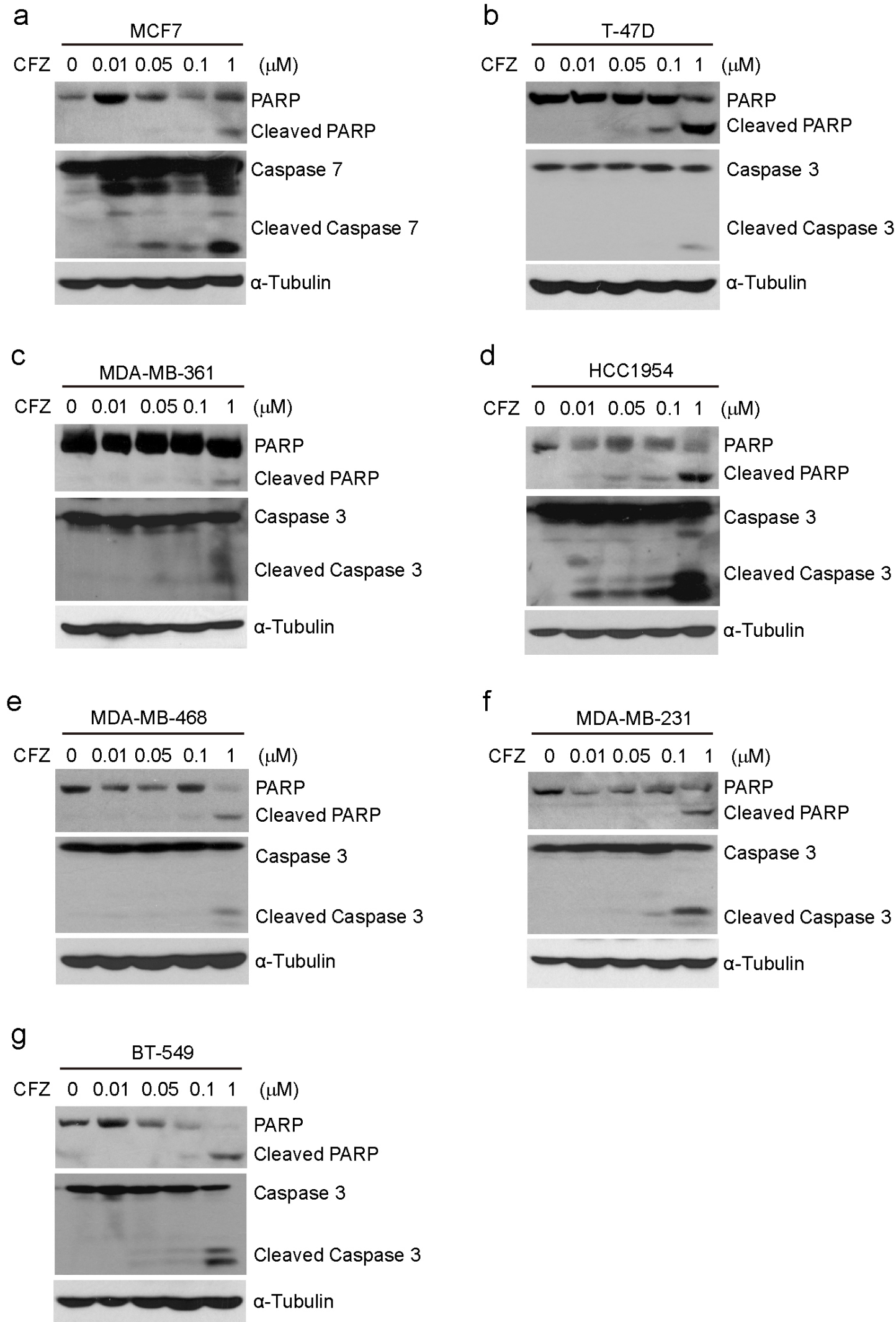

Figure 3: Carfilzomib induces apoptosis in breast cancer cells. a-g. Breast cancer cell lines MCF7, T-47D, MDA-MB-361, HCC1954, MDA-MB-468, MDA-MB-231, and BT-549 were treated with carfilzomib $(0,0.01 \mu \mathrm{M}, 0.05 \mu \mathrm{M}, 0.1 \mu \mathrm{M}$, or $1 \mu \mathrm{M})$ for $24 \mathrm{~h}$. Then whole cell lysates were subjected to SDS-PAGE and immunoblotted with antibodies against PARP and Caspase 3 (or Caspase 7) to detect apoptosis. $\alpha$-Tubulin was used as the loading control. 

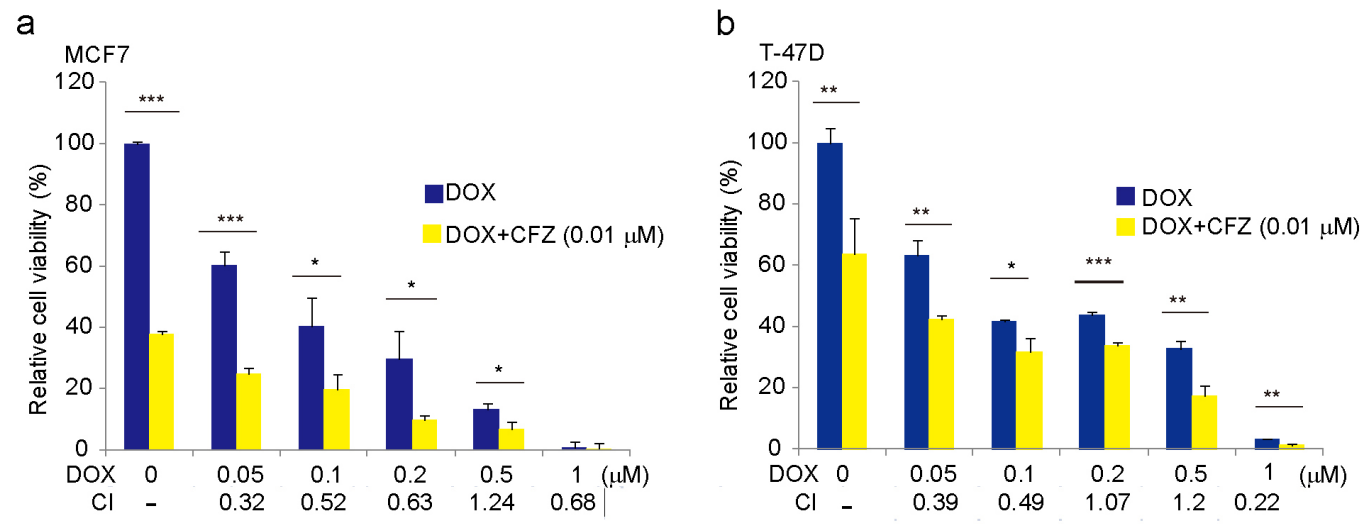

C
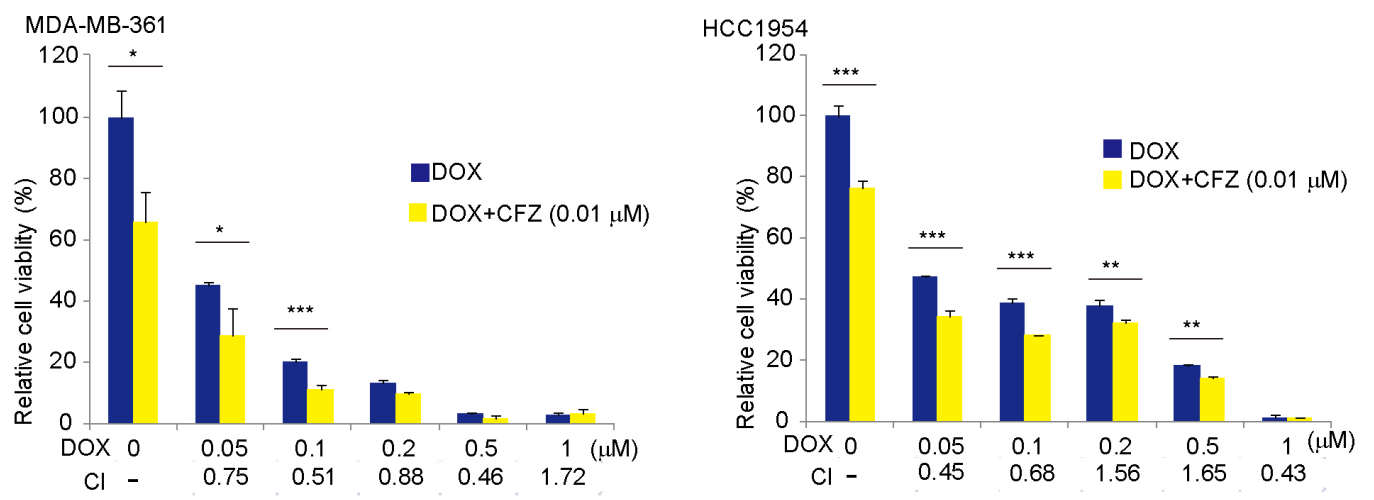

e

$f$
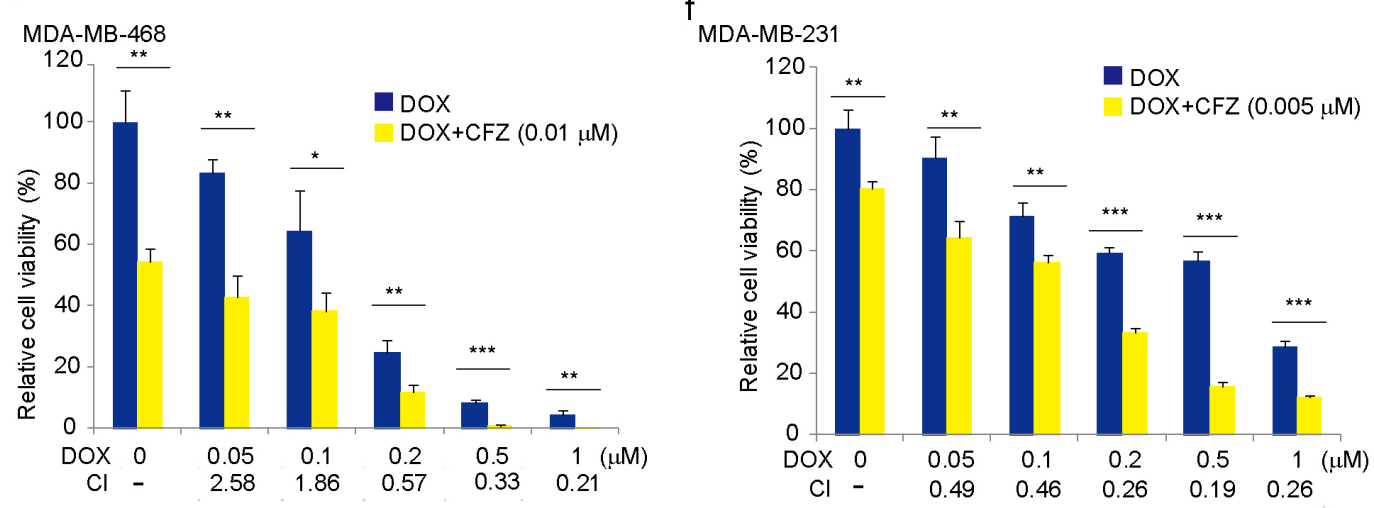

g

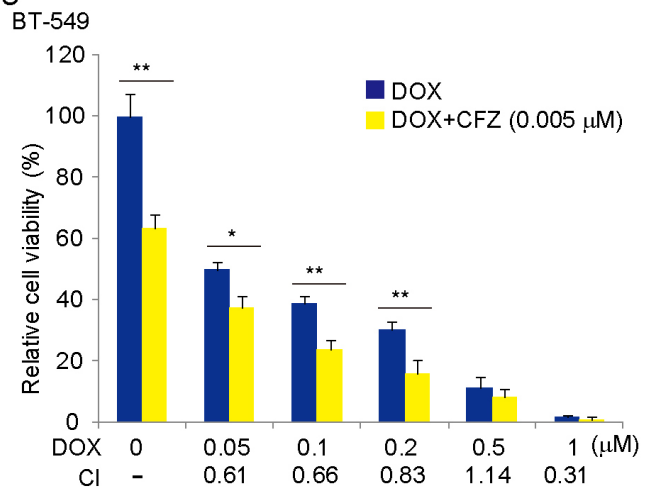

Figure 4: Carfilzomib enhances the cytotoxic effect of DOX on breast cancer cells. a-g. Breast cancer cell lines MCF7, T-47D, MDA-MB-361, HCC1954, MDA-MB-468, MDA-MB-231, and BT-549 were treated with DOX at the indicated concentrations with or without carfilzomib $0.01 \mu \mathrm{M}$ or $0.005 \mu \mathrm{M}$ for $72 \mathrm{~h}$. The cell viability was then measured by MTT assays. CI values were determined using CalcuSyn V2.0 software (BIOSOFT). The data were represented as mean \pm SD. $* P<0.05, * * P<0.01, * * * P<0.001$, by $t$-test. 
elucidate the potential mechanism of the enhanced effects of carfilzomib on DOX-induced apoptosis in breast cancer cells, we first assessed the effects of the combination of CFZ with DOX on the activity of NF- $\kappa \mathrm{B}, \mathrm{SAPK} / \mathrm{JNK}$, and p38 MAPK in 7 subtypes of breast cancer cell lines. The cells were cultured with CFZ alone, DOX alone or in combination with $\mathrm{CFZ}$ respectively. As shown in
Figure 6 and Supplementary Figure S3, CFZ alone could induce $\mathrm{SAPK} / \mathrm{JNK}$ and p38 MAPK phosphorylation in the tested cell lines. The addition of carfilzomib into DOX up-regulated DOX-induced SAPK/JNK and p38 MAPK phosphorylation, while DOX-induced I $\mathrm{B} \alpha$ degradation was suppressed by carfilzomib (Figure 6a-6g, Supplementary Figure S3a-S3g). These data demonstrate a

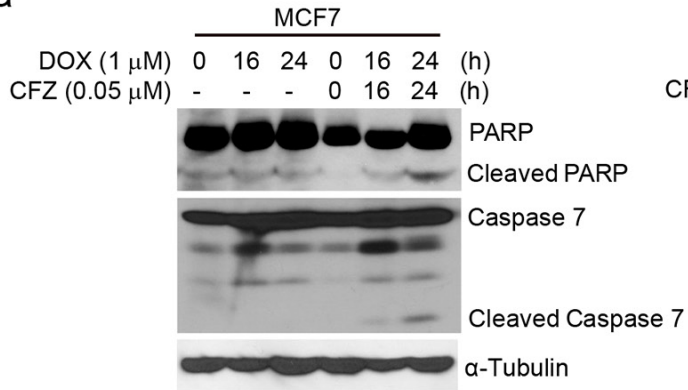

C

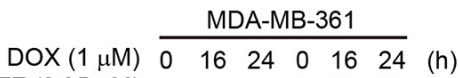
CFZ $(0.05 \mu \mathrm{M})-\quad-\quad-\quad 0 \quad 16 \quad 24(\mathrm{~h})$
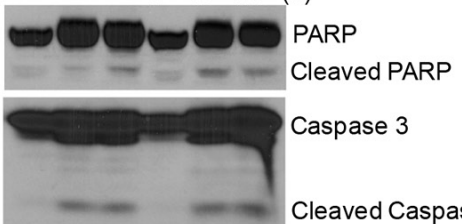

Caspase 3

Cleaved Caspase 3

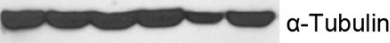

e

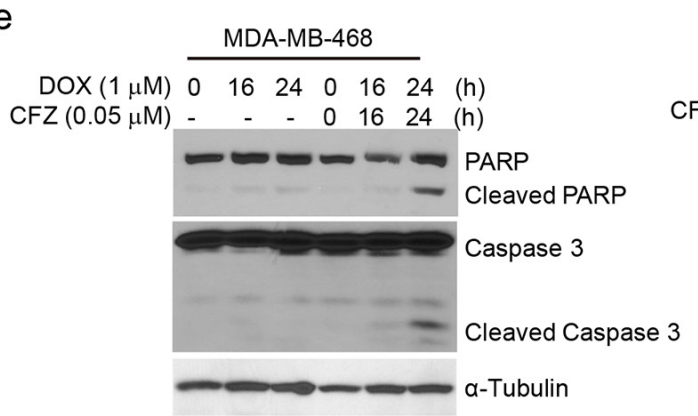

f

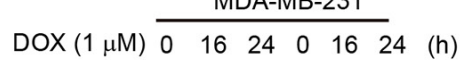

CFZ $(0.05 \mu \mathrm{M})$ - $\quad-\quad-\quad \begin{array}{lllll}0 & 16 & 24 & (\mathrm{~h})\end{array}$

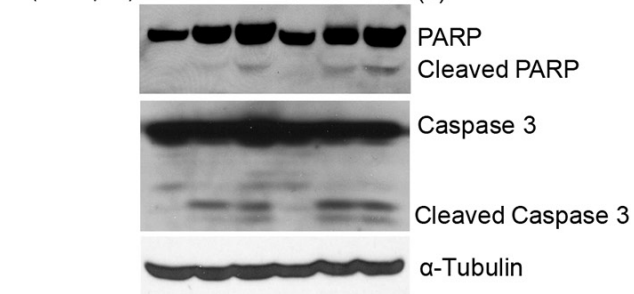

$\mathrm{b}$

$\operatorname{DOX}(1 \mu \mathrm{M}) \quad 0 \quad 16 \quad 24 \quad 0 \quad 16 \quad 24$ (h)

CFZ $(0.05 \mu \mathrm{M})$ - $\quad-\quad-\quad 01624(\mathrm{~h})$

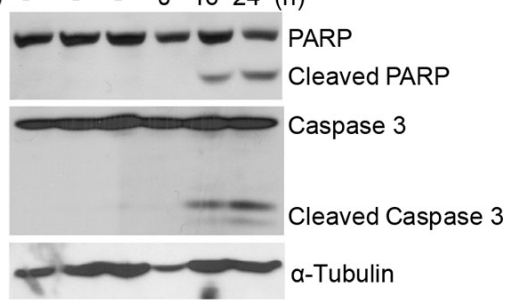

d

$\operatorname{DOX}(1 \mu \mathrm{M}) \overline{0} \begin{array}{lllllll}16 & 24 & 0 & 16 & 24 & (\mathrm{~h})\end{array}$

CFZ $(0.05 \mu \mathrm{M})$ - $\quad-\quad-\quad-\quad 0 \quad 1624$ (h)

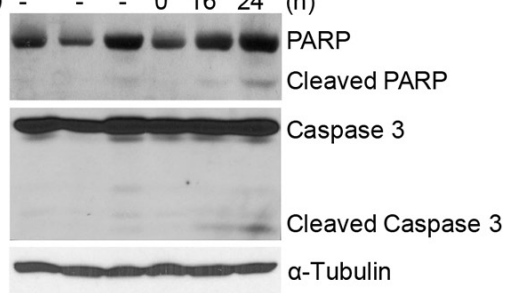

g

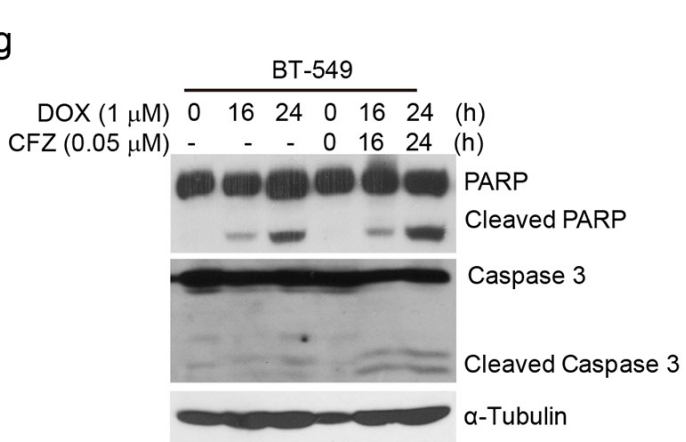

Figure 5: Carfilzomib strengthens DOX-induced apoptosis in breast cancer cells. a-g. Breast cancer cell lines MCF7, T-47D, MDA-MB-361, HCC1954, MDA-MB-468, MDA-MB-231, and BT-549 were treated with DOX $(1 \mu \mathrm{M})$ alone or combined with carfilzomib $(0.05 \mu \mathrm{M})$ for $0,16 \mathrm{~h}$, or $24 \mathrm{~h}$. Then whole cell lysates were subjected to SDS-PAGE and immunoblotted with antibodies against PARP and Caspase 3 (or Caspase 7) to detect apoptosis. $\alpha$-Tubulin was used as the loading control. 
a

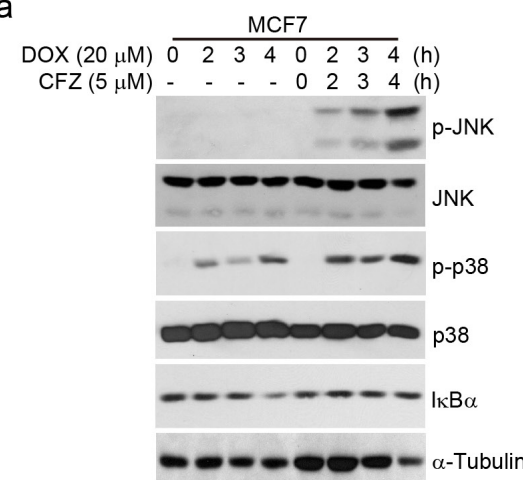

C

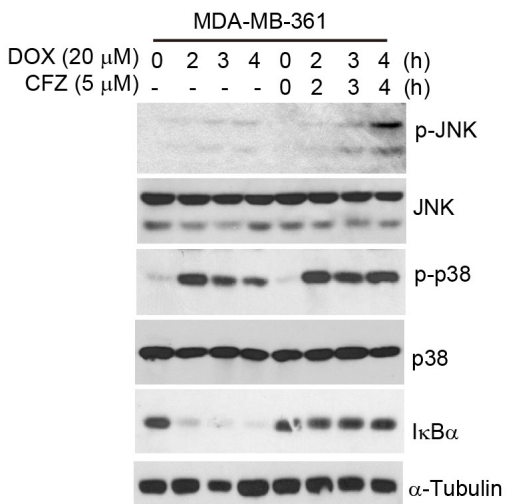

e

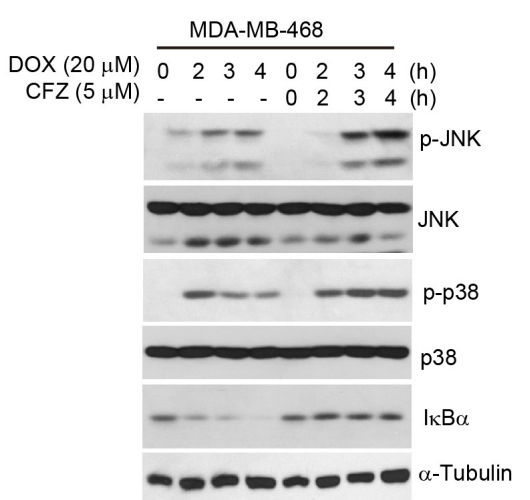

g

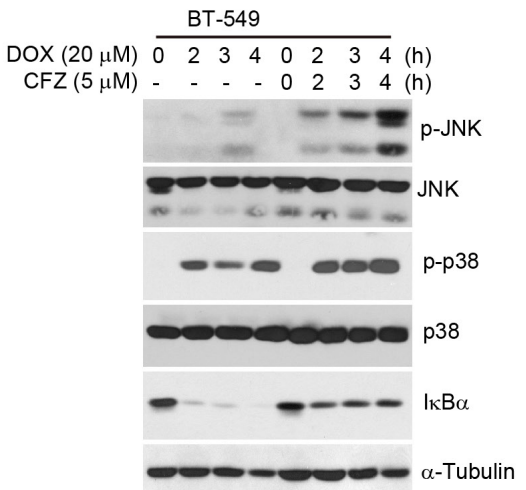

b

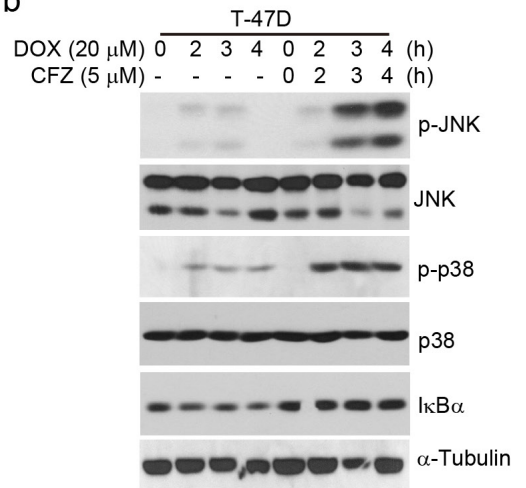

d $\begin{array}{rllllllll}\operatorname{DOX}(20 \mu \mathrm{M}) & 0 & 2 & 3 & 4 & 0 & 2 & 3 & 4 \\ \text { CFZ }(5 \mu \mathrm{M}) & - & - & - & - & 0 & 2 & 3 & 4\end{array}$

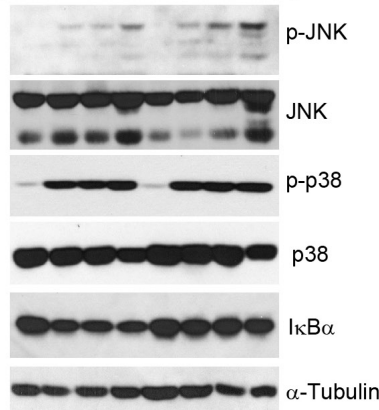

f

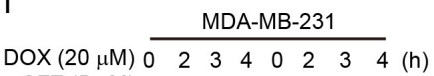

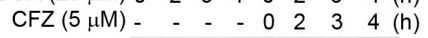

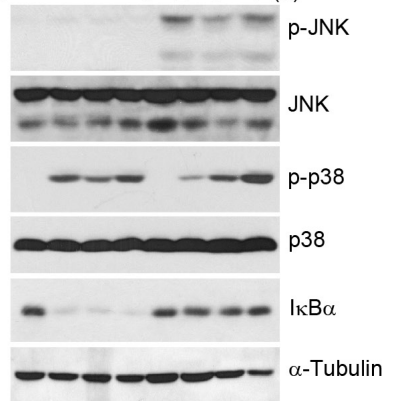

Figure 6: Carfilzomib enhances DOX-induced SAPK/JNK and p38 MAPK phosphorylation and inhibits DOX-induced I $\mathbf{B} \boldsymbol{\alpha}$ degradation in breast cancer cells. a-g. Breast cancer cell lines MCF7, T-47D, MDA-MB-361, HCC1954, MDA-MB-468, MDA-MB-231, and BT-549 were treated with DOX $(20 \mu \mathrm{M})$ alone or combined with carfilzomib $(5 \mu \mathrm{M})$ for $0,2 \mathrm{~h}, 3 \mathrm{~h}$ or $4 \mathrm{~h}$. Then whole cell lysates were subjected to SDS-PAGE and immunoblotted with antibodies against p-SARP/JNK, SARP/JNK, p-p38 MAPK, p38 MAPK, and IкB $\alpha . \alpha$-Tubulin was used as the loading control. 
that CFZ reinforced DOX-induced SAPK/JNK and p38 MAPK phosphorylation, whereas it inhibited DOXinduced $\mathrm{NF}-\kappa \mathrm{B}$ activation.

To investigate which pathway contributes to the enhanced effects of carfilzomib on DOX-induced apoptosis in breast cancer cells, we used specific inhibitors to individually block NF- $\mathrm{B}$ or MAPK pathways. The human estrogen and progesterone receptor-positive MCF7 is a well-established and widely used model system of breast cancer cells. We then examined the impact of the specific inhibitors on the proliferation of MCF7 cells. The results of MTT showed that the JNK-specific inhibitor SP600125, not p38 inhibitor SB203580, protected MCF7 from the enhanced effect of carfilzomib on DOX-induced cytotoxicity, and IкB kinase (IKK) inhibitor, PS-1145
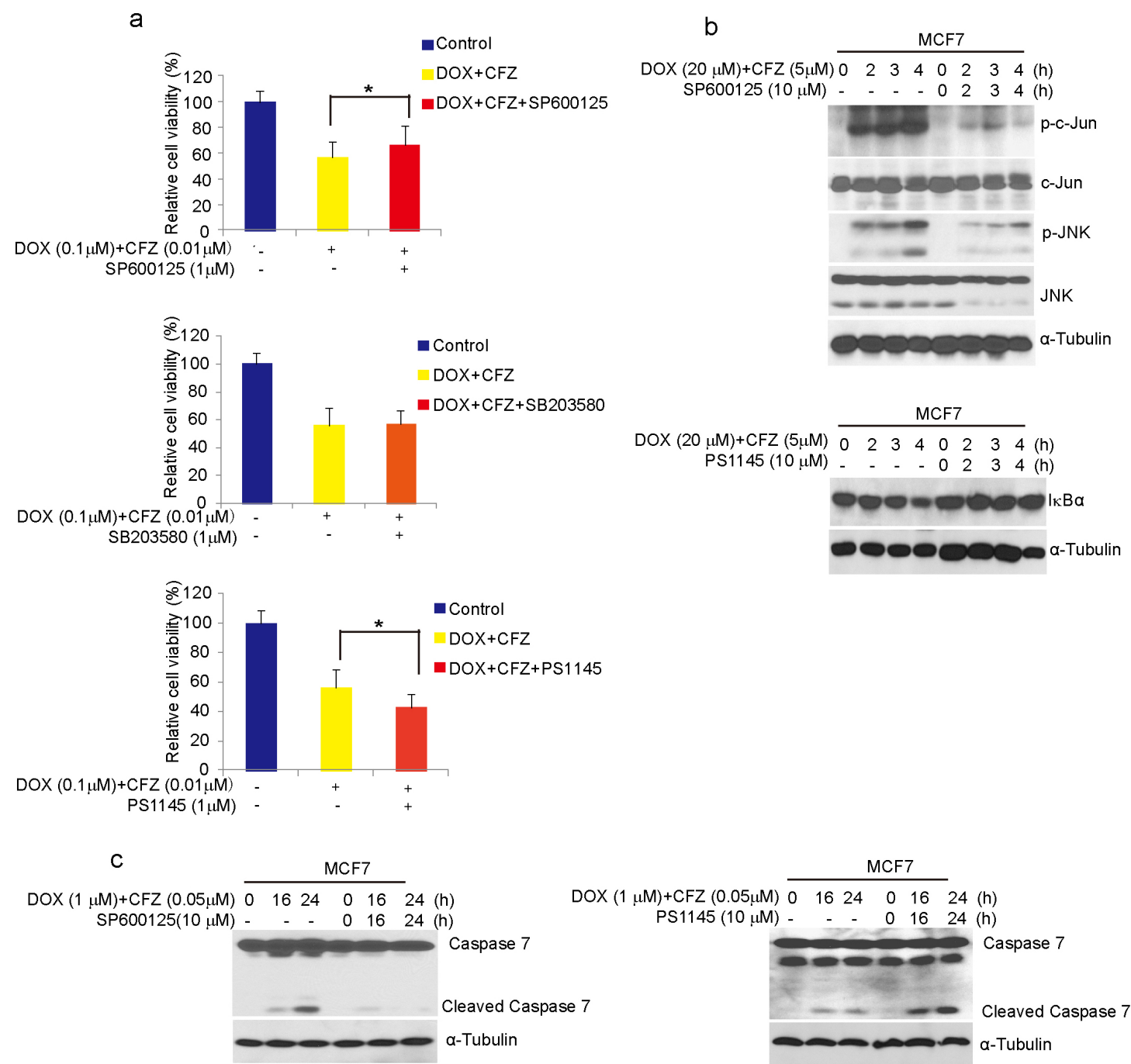

Figure 7: Carfilzomib enhances DOX-induced apoptosis through activation of SAPK/JNK pathway and inactivation of $\mathbf{N F - \kappa B}$ in breast cancer cells. a. MCF7 cells were left untreated or treated with DOX $(0.1 \mu \mathrm{M})$ plus carfilzomib $(0.01 \mu \mathrm{M})$, or in combination with specific pathway inhibitors (SP600125:JNK inhibitor $(1 \mu \mathrm{M})$; SB203580: p38 inhibitor (1 $\mu \mathrm{M})$; PS1145: IKK inhibitor $(1 \mu \mathrm{M})$ ) for $48 \mathrm{~h}$, then cell viability was measured by MTT assays. The data were represented as mean $\pm \mathrm{SD}$. ${ }^{*} P<0.05$ was indicated. b and c. MCF7 cells were incubated with DOX plus carfilzomib, or in combination with SP600125 or PS1145 for the time courses as indicated. Cells were lysed, subjected to SDS-PAGE, and immunoblotted with indicated antibodies. $\alpha$-Tubulin was used as the loading control. 
by activation of JNK-mediated apoptotic pathway and inhibition of $\mathrm{NF}-\kappa \mathrm{B}$.

\section{DISCUSSION}

The clinical success of the first-generation PI Bortezomib as an anticancer therapy for multiple myeloma and relapsed mantle cell lymphoma [28] has bolstered interest in the development of new generations of PIs, such as CFZ and NPI-0052. Development of PIs with distinct substrate selectivity, improved bioavailability and lower toxicity may open the door to widespread usage in solid tumors. Here, we examined the antitumor effect of CFZ on the proliferation of breast cancer cells. We found that CFZ has a high cytotoxic activity, accompanied with reduced cellular proliferation, attenuated colony forming ability, and increased apoptosis in a diverse panel of breast cancer cell lines representing all major molecular subtypes of breast cancers. IC50 values for the tested cell lines treated with CFZ were all in the low nanomolar range from $6.34 \mathrm{nM}$ (MDA-MB-361) to $76.51 \mathrm{nM}$ (T-47D), there was more than 10 -fold difference. This is similar to the reported CFZ IC50 values (0.2 nM -99.4 nM) in other solid tumor cell lines [11, 12], and it implies that the different subtypes of breast cancer cell lines might show the sensitivity difference to CFZ. It's worth mentioning that the anchorage-independent growth ability of HCC1954 was too poor to form macroscopic colonies in soft agar. These data suggest that CFZ alone could effectively restrain proteasome activity and has a significant antitumor effect on the tested breast cancer cells. Similarly, studies with CFZ have demonstrated that CFZ causes diminished cell proliferation and increased cell death across a variety of cancer cell lines such as those from lung cancer and anaplastic thyroid cancer $[11,12,29]$.
Increasingly, clinicians are challenged with resistance and toxicity to monotherapy or even in combination therapy. It is reported that DOX induces $\mathrm{NF}-\kappa \mathrm{B}$ activation and gives rise to DOX resistance in breast cancer and uterine cervical carcinoma [16, 30]. $\mathrm{NF}-\kappa \mathrm{B}$ activity has been implicated in several aspects of oncogenesis and chemoresistance $[31,32]$. These include its ability to induce transcription of genes associated with proliferation and survival, such as cyclin D1, c-IAP-2 and Bcl-xL [33, 34]. Chemoresistance caused by $\mathrm{NF}-\kappa \mathrm{B}$ activation is a common off-target effect and often necessitates discontinuation of therapy. For these reasons, in recent years, there has been a growing interest aiming at inhibiting $\mathrm{NF}-\kappa \mathrm{B}$ activity in cancer cells. In addition, DOX also induces the activation of p38 MAPK and JNK apoptosis signaling in breast cancer cells [35]. Combinations of proteasome inhibitors and other chemotherapeutic agents have been examined for use in cancer therapy. In imatinib-sensitive and -resistant chronic myeloid leukemia models, CFZ showed a synergistic effect in combination with tyrosine kinase inhibitors [36]. Dual drug-loaded liposomes containing CFZ and DOX exhibited synergistic efficacy in multiple myeloma in vitro and were more efficacious in inhibiting tumor growth in vivo [37]. As shown, CIs for most combinations of CFZ and DOX were far lower than 1.0, indicating synergistic effects on breast cancer cells, and the combination of the lower doses of CFZ and DOX significantly and synergistically induced increasingly cytotoxic effects and apoptosis in breast cancer cells by preventing inhibitory factor $\kappa \mathrm{B} \alpha$ lpha $(\mathrm{I} \kappa \mathrm{B} \alpha)$ degradation in the NF- $\kappa \mathrm{B}$ signal pathway and activating JNK apoptosis signaling not p38 MAPK in our assays. These data support a model described in Figure 8. It demonstrated

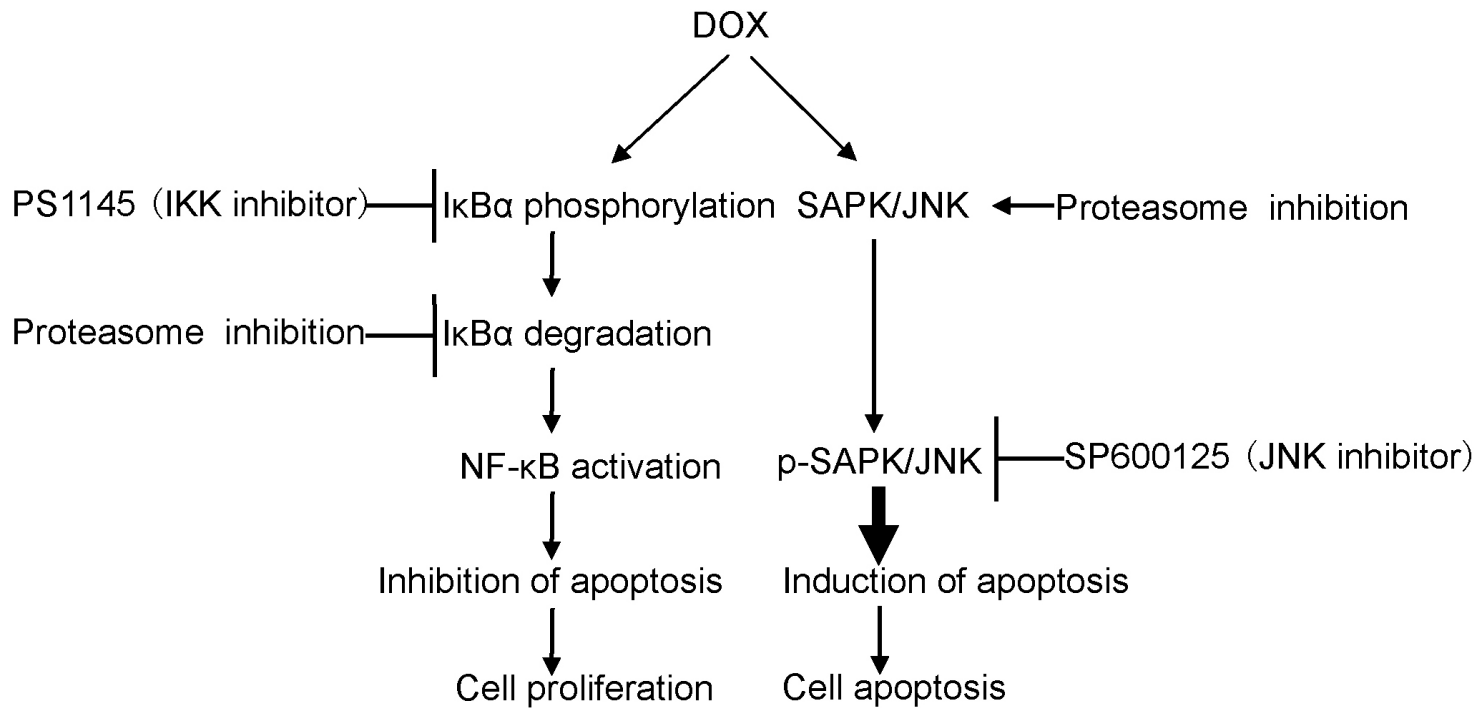

Figure 8: A proposed schematic of carfilzomib's cytotoxic effect on breast cancer. The cartoon depicts the proposed signaling events from proteasome inhibition, leading to NF- $\mathrm{BB}$ inactivation and SARP/JNK activation in breast cancer cells and, ultimately, cell death. 
that though breast cancer cells showed higher sensitivity to CFZ, breast cancer cells were further sensitized by the combination of CFZ with DOX treatment. CFZ may sensitize breast cancer cells to DOX chemotherapy and thus lessen DOX resistance and toxicity. In kind, some reports suggest that proteasome inhibitors exacerbated DOX-induced cytotoxicity in cardiomyocytes [38] and sensitized leukemia cells and breast cancer cells to DOX by suppressing NF- $\kappa \mathrm{B}$ and activating JNK apoptosis signaling pathway $[39,40]$.

A study that combined treatment of bortezomib and Lapatinib, an inhibitor of epidermal growth factor receptor (EGFR) and HER2 tyrosine kinases, showed a synergistic effect in HER2-overexpressing breast cancer cells [41]. In our work, carfilzomib alone or in combination with DOX showed potent cytotoxic effects and induced apoptosis in HER2-positive MDA-MB-361 and HCC1954 breast cancer cells. CFZ may also be combined with inhibitors to other receptor tyrosine kinases to increase therapeutic efficacy for breast cancer patients. Another paper reported that Nrf2, heme oxygenase 1 (HO-1), and GSH are upregulated in bortezomib-resistant neuroblastoma [42]. In future studies, the use of PIs and the development of novel strategies to combat cancer that inhibit multiple targets may be indispensable in order to model better treatment options for breast cancer patients.

In conclusion, by using a panel of breast cancer cell lines, we provided compelling evidence that carfilzomib alone could suppress the proliferation and induce apoptosis in breast cancer cells and enhance the cytotoxic effect of DOX and DOX-induced apoptosis in combination by preventing $\mathrm{I} \kappa \mathrm{B} \alpha$ degradation in the NF$\kappa \mathrm{B}$ signal pathway and activating JNK apoptotic signaling. This study suggests that carfilzomib might serve as an effective drug in the potential combination therapy for breast cancer patients with chemoresistance.

\section{MATERIALS AND METHODS}

\section{Cell lines and cell culture}

The human breast cancer cell lines MCF7, T47D, MDA-MB-361, HCC1954, MDA-MB-468, MDAMB-231, and BT-549 were obtained from American Type Culture Collection (ATCC, Manassas, VA, USA). MCF7, MDA-MB-361 and MDA-MB-231 cells were routinely cultured in Dulbecco's modified Eagle's medium (DMEM, Lonza, Walkersville, MD, USA), and T-47D, HCC1954, MDA-MB-468 and BT-549 were maintained in RPMI-1640 medium (Lonza), all supplemented with 10\% fetal bovine serum (FBS, Sigma-Aldrich Co. LLC. St. Louis, MO, USA), 100 units/ml penicillin, and 100 $\mathrm{mg} / \mathrm{ml}$ streptomycin. All cells were cultured at $37^{\circ} \mathrm{C}$ in a humidified atmosphere of $5 \% \mathrm{CO}_{2}$.

\section{Antibodies and reagents}

The antibodies against $\mathrm{I} \kappa \mathrm{B} \alpha$ (9242), phosphoSAPK/JNK (Thr183/Tyr185) (9251), SAPK/JNK (9258), phospho-p38 MAP kinase (Thr180/Tyr182) (9211), p38 MAP kinase (8690), PARP (9532), Caspase 3 (9662), Caspase 7 (12827), mouse (7076) and rabbit (7074) were purchased from Cell Signaling Technology (Danvers, MA, USA). The antibody against $\alpha$-tubulin (10D8) (sc-53646) was purchased from Santa Cruz Biotechnology (Dallas, TX, USA). DOX (D1515) was obtained from SigmaAldrich. Carfilzomib (C3022) was purchased from LC Lab (Woburn, MA, USA).

\section{Cytotoxicity assay}

Cell cytotoxicity assays were performed using MTT (MKBH9792V) (Sigma-Aldrich, Spring, TX, USA) following the manufacturer's instructions. Briefly, the cells were seeded in 96-well plates at the density of $5 \times$ $10^{3}$ cells per well. After $24 \mathrm{~h}$ of incubation at $37^{\circ} \mathrm{C}$, cells were either allowed to grow in media alone or in media containing increasing concentrations of carfilzomib, DOX, or the combination of the two agents. 72 hours later, cells were observed and photographed by optical microscope. $10 \mu \mathrm{l}$ of MTT was added into each well, and the cells were incubated for another $2 \mathrm{~h}$. Then, $50 \mu \mathrm{l}$ of DMSO was added into each well, and the cells were incubated for another 10 $\min$. The absorbance of each well was measured at $540 \mathrm{~nm}$ and plotted for the cell viability curve. Each experiment was performed in triplicates.

\section{Determination of synergy}

Cells were seeded in triplicate $\left(5 \times 10^{3} /\right.$ well $)$ in 96-well plates and allowed to recover overnight. The cells were then treated for $72 \mathrm{~h}$ with varying doses of individual drugs alone or varying doses of non-constant ratio of two drugs together. Untreatment was used as a control. Following performance of MTT assays, data were analyzed and combination indexes (CIs) were determined according to the method of Chou and Talalay [43] using CalcuSyn V2.0 software (BIOSOFT). CI values lower than 1.0 were considered evidence of synergism.

\section{Colony formation assay}

Cells were seeded in 12-well plates at $2 \times 10^{3}$ cells per well. 48 or 72 hours later, cells were incubated with carfilzomib at $0,0.005 \mu \mathrm{M}$, or $0.01 \mu \mathrm{M}$ for $72 \mathrm{~h}$, and then cultured in drug-free medium for about two weeks. After that, cells were fixed and stained with methanol/crystal violet for $10 \mathrm{~min}$ and photographed. Each experiment was performed in triplicate. 


\section{Anchorage-independent growth assay}

Cell anchorage-independent growth ability was assessed by soft agar assay. In a 6-well plate, the bottom layer was made of $0.5 \%$ agar, $2 \mathrm{ml}$ in each well, cooled to semi-solid. For the top layer, cells were mixed with $0.3 \%$ agar, $1.5 \mathrm{ml}$ in each well at the density of $5 \times 10^{3}$ cells per well, mixed with carfilzomib at concentrations of $0,0.005 \mu \mathrm{M}$, or $0.01 \mu \mathrm{M}$. Cells grew at $37^{\circ} \mathrm{C}$ for three weeks until the colonies were visible to the naked eye, were stained with crystal violet for $2 \mathrm{~h}$ and were photographed. The colonies were counted by Quantity One software (Bio-Rad Laboratories, Inc., Hercules, CA, USA) and plotted. Each experiment was performed in triplicate.

\section{Immunoblotting}

For immunoblotting, after each treatment, cells were washed twice with ice-cold PBS, and spun down. The cell pellets were dissolved in lysis buffer for $30 \mathrm{~min}$ at $4^{\circ} \mathrm{C}[50 \mathrm{mM}$ Tris- $\mathrm{HCl}$ at $\mathrm{pH} 7.4,150 \mathrm{mM} \mathrm{NaCl}, 1$ mM EDTA, $1 \%$ NP-40, $0.25 \%$ sodium deoxycholate, $1 \mathrm{mM}$ phenylmethylsulfonyl fluoride (PMSF), $1 \mathrm{mM}$ benzamidine, $10 \mu \mathrm{g} / \mathrm{mL}$ leupeptin, $1 \mathrm{mM}$ dithiothreitol (DTT), $10 \mathrm{mM}$ sodium fluoride $(\mathrm{NaF}), 0.1 \mathrm{mM}$ sodium orthovanadate $(\mathrm{OV})$, phosphatase inhibitor cocktail 2 and 3 (p5726 and p0044, Sigma-Aldrich)]. The solutions were centrifuged at $13,000 \mathrm{rpm}$ for $15 \mathrm{~min}$, and the supernatants were collected as cell lysates. The cell lysates were subjected to $10 \%$ or $15 \%$ SDS-PAGE electrophoresis and transferred to polyvinylidene fluoride (PVDF) membranes, followed by immunoblotting with the primary antibodies and the horseradish peroxidaseconjugated secondary antibodies against rabbit or mouse IgG. The membranes were developed using the ECL Western blotting system (Thermo Fisher Scientific Inc., Rockford, IL, USA) according to the manufacturer's instructions.

\section{Flow cytometry and propidium iodide (PI) staining assay}

The experiment was performed as the following. Breast cancer cell lines were seeded in $6 \mathrm{~cm}$ dishes and treated with carfilzomib of $0,0.05 \mu \mathrm{M}$, or $1 \mu \mathrm{M}$ for 24 h. Cells were trypsinized, resuspended in the medium with $10 \% \mathrm{FBS}$, and centrifuged at $1500 \mathrm{rpm}$ for $5 \mathrm{~min}$ at $4^{\circ} \mathrm{C}$. Cells were then washed with PBS for three times, resuspended in $200 \mu \mathrm{l}$ of PI staining solution (51-66211E; BD Biosciences), and then transferred into new $5 \mathrm{ml}$ culture tubes with filter. The tubes were gently vortexed and incubated for $15 \mathrm{~min}$ at $\mathrm{RT}\left(25^{\circ} \mathrm{C}\right)$ in the dark, then the samples were analyzed by flow cytometry within $1 \mathrm{~h}$. As viable cells with intact membranes resist PI staining, only the membranes of dead cells are subject to PI staining. Unstained cells were used as a negative control and untreated cells were used as a control for treated cells. Then analysis was performed on a LSRII flow cytometer (BD Biosciences) using BD FACDiva software v. 6.0.

\section{Statistical analysis}

Statistical analysis was performed using GraphPad Prism 5 software. All values were presented as mean \pm standard deviation (SD). $P$-values $<0.05$ were considered to be statistically significant. Student's $t$-test (two-tailed) or ANOVA (Dunnett's multiple comparison post-test) were used to analyze the difference between the drug treatment groups and control group.

\section{ACKNOWLEDGMENTS}

This work was supported by the University Cancer Foundation via the Institutional Research Grant Program at the University of Texas MD Anderson Cancer Center (to HZ). Yonghua Shi was sponsored by China Scholarship Council (\#201408655107). We thank Davis Ingram for scientific editing of the manuscript.

\section{CONFLICTS OF INTEREST}

The authors declare no conflicts of interest.

\section{Author contributions}

Hong Zhang, Yonghua Shi, Yang Yu and Zhenyu Wang developed the study concept and design. Yonghua Shi, Zhenyu Wang, Hao Wang, Shayahati Bieerkehazhi and Yanling Zhao performed experiments and collected data. Yonghua Shi, Hao Wang, Lale Suzuk and Hong Zhang analyzed the data. Yonghua Shi and Hong Zhang drafted the manuscript. All authors approved the final version of the manuscript for submission.

\section{REFERENCES}

1. Glickman MH, Ciechanover A. The ubiquitin-proteasome proteolytic pathway: destruction for the sake of construction. Physiol Rev. 2002; 82:373-428.

2. Demo SD, Kirk CJ, Aujay MA, Buchholz TJ, Dajee M, Ho MN, Jiang J, Laidig GJ, Lewis ER, Parlati F. Antitumor activity of PR-171, a novel irreversible inhibitor of the proteasome. Cancer research. 2007; 67:6383-6391.

3. Zhang $\mathrm{J}, \mathrm{Wu} \mathrm{P}, \mathrm{Hu}$ Y. Clinical and marketed proteasome inhibitors for cancer treatment. Current medicinal chemistry. 2013; 20:2537-2551.

4. Driscoll JJ, Woodle ES. (2012). Targeting the ubiquitin+ proteasome system in solid tumors. Seminars in hematology: Elsevier), pp. 277-283. 
5. Hoeller D, Dikic I. Targeting the ubiquitin system in cancer therapy. Nature. 2009; 458:438-444.

6. Richardson P. Clinical update: proteasome inhibitors in hematologic malignancies. Cancer treatment reviews. 2003; 29:33-39.

7. Siegel DS. From clinical trials to clinical practice: singleagent carfilzomib adverse events and their management in patients with relapsed and/or refractory multiple myeloma. Therapeutic advances in hematology. 2013; 4:354-365.

8. Chao A, Wang T-H. Molecular mechanisms for synergistic effect of proteasome inhibitors with platinum-based therapy in solid tumors. Taiwanese Journal of Obstetrics and Gynecology. 2016; 55:3-8.

9. Jakubowiak AJ. Evolution of carfilzomib dose and schedule in patients with multiple myeloma: a historical overview. Cancer treatment reviews. 2014; 40:781-790.

10. Arastu-Kapur S, Anderl JL, Kraus M, Parlati F, Shenk KD, Lee SJ, Muchamuel T, Bennett MK, Driessen C, Ball AJ. Nonproteasomal targets of the proteasome inhibitors bortezomib and carfilzomib: a link to clinical adverse events. Clinical Cancer Research. 2011; 17:2734-2743.

11. Baker AF, Hanke NT, Sands BJ, Carbajal L, Anderl JL, Garland LL. Carfilzomib demonstrates broad anti-tumor activity in pre-clinical non-small cell and small cell lung cancer models. J Exp Clin Cancer Res. 2014; 33:111.

12. Mehta A, Zhang L, Boufraqech M, Zhang Y, Patel D, Shen M, Kebebew E. Carfilzomib is an effective anticancer agent in anaplastic thyroid cancer. Endocrine-related cancer. 2015; 22:319-329.

13. Si W, Li Y, Han Y, Zhang F, Wang Y, Li Y, Linghu RX, Zhang X, Yang J. Epidemiological and Clinicopathological Trends of Breast Cancer in Chinese Patients During 1993 to 2013: A Retrospective Study. Medicine (Baltimore). 2015; 94:e820

14. Asghar $U$, Meyer $T$. Are there opportunities for chemotherapy in the treatment of hepatocellular cancer? Journal of hepatology. 2012; 56:686-695.

15. Xu F, Wang F, Yang $T$, Sheng $Y$, Zhong $T$, Chen Y. Differential drug resistance acquisition to doxorubicin and paclitaxel in breast cancer cells. Cancer Cell Int. 2014; 14:538.

16. Esparza-López J, Medina-Franco H, Escobar-Arriaga E, León-Rodríguez E, Zentella-Dehesa A, Ibarra-Sánchez MJ. Doxorubicin induces atypical NF- $\kappa \mathrm{B}$ activation through c-Abl kinase activity in breast cancer cells. Journal of cancer research and clinical oncology. 2013; 139:1625-1635.

17. Neve RM, Chin K, Fridlyand J, Yeh J, Baehner FL, Fevr T, Clark L, Bayani N, Coppe JP, Tong F, Speed T, Spellman PT, DeVries S, Lapuk A, Wang NJ, Kuo WL, et al. A collection of breast cancer cell lines for the study of functionally distinct cancer subtypes. Cancer Cell. 2006; 10:515-527.
18. Holliday DL, Speirs V. Choosing the right cell line for breast cancer research. Breast Cancer Res. 2011; 13:215.

19. Perou CM, Sorlie T, Eisen MB, van de Rijn M, Jeffrey SS, Rees CA, Pollack JR, Ross DT, Johnsen H, Akslen LA, Fluge O, Pergamenschikov A, Williams C, Zhu SX, Lonning PE, Borresen-Dale AL, et al. Molecular portraits of human breast tumours. Nature. 2000; 406:747-752.

20. Han B, Yao W, Oh YT, Tong JS, Li S, Deng J, Yue P, Khuri FR, Sun SY. The novel proteasome inhibitor carfilzomib activates and enhances extrinsic apoptosis involving stabilization of death receptor 5. Oncotarget. 2015; 6:1753217542. doi: 10.18632/oncotarget.3947.

21. Saba NS, Liu D, Herman SE, Underbayev C, Tian X, Behrend D, Weniger MA, Skarzynski M, Gyamfi J, Fontan L, Melnick A, Grant C, Roschewski M, Navarro A, Bea $\mathrm{S}$, Pittaluga S, et al. Pathogenic role of B-cell receptor signaling and canonical NF- $\mathrm{KB}$ activation in mantle cell lymphoma. Blood. 2016.

22. Guo Y, Lin D, Zhang M, Zhang X, Li Y, Yang R, Lu Y, Jin X, Yang M, Wang M, Zhao S, Quan C. CLDN6-induced apoptosis via regulating ASK1-p38/JNK signaling in breast cancer MCF-7 cells. Int J Oncol. 2016; 48:2435-2444.

23. von Koschembahr AM, Swope VB, Starner RJ, AbdelMalek ZA. Endothelin-1 protects human melanocytes from UV-induced DNA damage by activating JNK and p38 signalling pathways. Exp Dermatol. 2015; 24:269-274.

24. Zhen Y, Ding C, Sun J, Wang Y, Li S, Dong L. Activation of the calcium-sensing receptor promotes apoptosis by modulating the JNK/p38 MAPK pathway in focal cerebral ischemia-reperfusion in mice. Am J Transl Res. 2016; 8:911-921.

25. Finn NA, Kemp ML. Pro-oxidant and antioxidant effects of $\mathrm{N}$-acetylcysteine regulate doxorubicin-induced NF- $\mathrm{kB}$ activity in leukemic cells. Mol Biosyst. 2012; 8:650-662.

26. Lopez de Vergara O, Pablos R, Ruiz-Sanz MB, Ruiz-Larrea JI, Navarro R. Characterization of the NF-?B signaling triggered by doxorubicin. Free Radic Biol Med. 2014; 75:S38.

27. Yan Y, Furumura M, Gouya T, Iwanaga A, Teye K, Numata S, Karashima T, Li XG, Hashimoto T. Shikonin Promotes Skin Cell Proliferation and Inhibits Nuclear Factor- $\kappa \mathrm{B}$ Translocation via Proteasome Inhibition In Vitro. Chin Med J (Engl). 2015; 128:2228-2233.

28. Tobinai K. Proteasome inhibitor, bortezomib, for myeloma and lymphoma. Int J Clin Oncol. 2007; 12:318-326.

29. Hanke NT, Garland LL, Baker AF. Carfilzomib combined with suberanilohydroxamic acid (SAHA) synergistically promotes endoplasmic reticulum stress in non-small cell lung cancer cell lines. J Cancer Res Clin Oncol. 2016; 142:549-560.

30. Liang L, Fan Y, Cheng J, Cheng D, Zhao Y, Cao B, Ma L, An L, Jia W, Su X, Yang J, Zhang H. TAK1 ubiquitination 
regulates doxorubicin-induced $\mathrm{NF}-\kappa \mathrm{B}$ activation. Cell Signal. 2013; 25:247-254.

31. DiDonato JA, Mercurio F, Karin M. NF-kB and the link between inflammation and cancer. Immunological reviews. 2012; 246:379-400.

32. Zhang J, Xin X, Chen Q, Xie Z, Gui M, Chen Y, Lin L, Feng J, Li Q, Ding J. Oligomannurarate sulfate sensitizes cancer cells to doxorubicin by inhibiting atypical activation of NF- $\kappa \mathrm{B}$ via targeting of Mre11. International Journal of Cancer. 2012; 130:467-477.

33. Karin M. Nuclear factor- $\kappa \mathrm{B}$ in cancer development and progression. Nature. 2006; 441:431-436.

34. Karin M, Greten FR. NF- $\kappa B$ : linking inflammation and immunity to cancer development and progression. Nature Reviews Immunology. 2005; 5:749-759.

35. Kanno SI, Yomogida S, Tomizawa A, Yamazaki H, Ukai K, Mangindaan RE, Namikoshi M, Ishikawa M. Combined effect of papuamine and doxorubicin in human breast cancer MCF-7 cells. Oncol Lett. 2014; 8:547-550.

36. Crawford LJ, Chan ET, Aujay M, Holyoake TL, Melo JV, Jorgensen HG, Suresh S, Walker B, Irvine AE. Synergistic effects of proteasome inhibitor carfilzomib in combination with tyrosine kinase inhibitors in imatinib-sensitive and -resistant chronic myeloid leukemia models. Oncogenesis. 2014; 3:e90.

37. Ashley JD, Quinlan CJ, Schroeder VA, Suckow MA, Pizzuti VJ, Kiziltepe T, Bilgicer B. Dual Carfilzomib and Doxorubicin-Loaded Liposomal Nanoparticles for Synergistic Efficacy in Multiple Myeloma. Molecular cancer therapeutics. 2016; 15:1452-1459.
38. Spur EM, Althof N, Respondek D, Klingel K, Heuser A, Overkleeft HS, Voigt A. Inhibition of chymotryptic-like standard proteasome activity exacerbates doxorubicininduced cytotoxicity in primary cardiomyocytes. Toxicology. 2016; 353-354:34-47.

39. Ortiz-Lazareno PC, Bravo-Cuellar A, Lerma-Diaz JM, JaveSuarez LF, Aguilar-Lemarroy A, Dominguez-Rodriguez JR, Gonzalez-Ramella O, De Celis R, Gomez-Lomeli P, Hernandez-Flores G. Sensitization of U937 leukemia cells to doxorubicin by the MG132 proteasome inhibitor induces an increase in apoptosis by suppressing NF- $\mathrm{kB}$ and mitochondrial membrane potential loss. Cancer Cell Int. 2014; 14:13.

40. Wang H, Yu Y, Jiang Z, Cao WM, Wang Z, Dou J, Zhao Y, Cui Y, Zhang H. Next-generation proteasome inhibitor MLN9708 sensitizes breast cancer cells to doxorubicininduced apoptosis. Scientific reports. 2016; 6:26456.

41. Ma C, Niu X, Luo J, Shao Z, Shen K. Combined effects of lapatinib and bortezomib in human epidermal receptor 2 (HER2)-overexpressing breast cancer cells and activity of bortezomib against lapatinib-resistant breast cancer cells. Cancer Sci. 2010; 101:2220-2226.

42. Furfaro AL, Piras S, Domenicotti C, Fenoglio D, De Luigi A, Salmona M, Moretta L, Marinari UM, Pronzato MA, Traverso N, Nitti M. Role of Nrf2, HO-1 and GSH in Neuroblastoma Cell Resistance to Bortezomib. PLoS One. 2016; 11:e0152465.

43. Chou T-C, Talalay P. Quantitative analysis of dose-effect relationships: the combined effects of multiple drugs or enzyme inhibitors. Advances in enzyme regulation. 1984; 22:27-55. 